\title{
EVALUASI KUALITAS PRODUK PADA INDUSTRI KERAJINAN DENGAN METODE QUALITY FUNCTION DEPLOYMENT (QFD) (Studi kasus pada industri kerajinan batik di Yogyakarta)
}

\author{
Melani Anggraini \\ Fakultas Teknik, Program Studi Teknik Industri Universitas Malahayati \\ Bandar Lampung 35153 \\ melani.malahayati@gmail.com
}

\begin{abstract}
Abstrak
Teknologi merupakan salah satu faktor penting dalam meningkatkan perkembangan suatu industri. Salah satu cara untuk meningkatkan perkembangan industri adalah dengan mengevaluasi kualitas produk. Evaluasi kualitas produk dapat dianalisis dengan memetakan prioritas keinginan konsumen untuk meningkatkan performa teknologi. Penelitian ini bertujuan mengevaluasi kualitas produk pada suatu industri kerajinan dengan melihat kelebihan dan kekurangan teknologi yang dimiliki dibandingkan dengan pesaing menggunakan metode Quality Function Deployment (QFD). Quality Function Deployment (QFD) merupakan suatu metode perencanaan dan pengembangan produk atau jasa yang memungkinkan sebuah tim pengembang untuk lebih menspesifikasikan keinginan dan kebutuhan dari pelanggan. Objek penelitian dilakukan di industri kerajinan batik di Yogyakarta. Pengrajin batik yang dianalisis dalam penelitian ini adalah Batik A dengan kompetitornya Batik B dan Batik C. Hasil penelitian menunjukkan bahwa hal utama yang harus dilakukan untuk memperbaiki kualitas produk batik berturut-turut: inovasi desain, teknik pembatikan, inovasi warna, teknik pewarnaan, dan inovasi motif.
\end{abstract}

Kata kunci: Evaluasi Kualitas Produk, Quality Function Deployment (QFD), Batik.

\section{PENDAHULUAN}

Industri merupakan salah satu sektor penggerak ekonomi yang secara nyata mampu memberikan sumbangsih yang cukup besar terhadap pendapatan nasional maupun daerah. Diberlakukannya pasar bebas juga memberikan tantangan tersendiri bagi Indonesia untuk dapat bersaing dalam menguasai pasar dalam negeri. Dari beberapa alasan yang ada, mengharuskan para pelaku industri untuk meningkatkan daya saing industri, salah satunya dengan mengevaluasi kualitas produk. Kualitas produk merupakan keseluruhan karakteristik produk dan jasa yang dalam pemakaiannya sesuai dengan kebutuhan dan harapan pelanggan. Penelitian ini bertujuan mengevaluasi kualitas produk pada suatu industri kerajinan dengan melihat kelebihan dan kekurangan teknologi yang dimiliki dibandingkan dengan pesaing lain dengan fokus pada kebutuhan pelanggan dan harapan dari produk menggunakan metode Quality Function Deployment (QFD). QFD membantu menunjukkan dengan tepat daerah-daerah atau masalah-masalah yang menjadi pertimbangan dari konsumen, selain itu juga sebagai alat perencana yang penting untuk pengenalan produk baru dan peningkatan mutu produk yang ada. Obyek penelitian dalam penelitian ini adalah industri kerajinan batik di Yogyakarta.

\section{TINJAUAN PUSTAKA}

Cohen (1995), Quality Function Deployment (QFD) adalah metode terstruktur yang digunakan dalam proses perencanaan dan pengembangan produk untuk menetapkan spesifikasi kebutuhan dan keinginan konsumen, serta mengevaluasi secara sistematis kapabilitas suatu produk atau jasa dalam memenuhi kebutuhan dan keinginan konsumen. Tujuan dari Quality Function Deployment tidak hanya memenuhi sebanyak mungkin harapan pelanggan, tapi juga berusaha melampaui harapan-harapan pelanggan sebagai cara untuk berkompetensi dengan saingannya, sehingga diharapkan konsumen terpuaskan.

Penelitian tentang perbandingan antara Quality Function Deployment dengan Fuzzy Quality Function Deployment pernah dilakukan oleh Irawan (2002) untuk memenuhi syarat 
memperoleh gelar Magister Teknik Institut Teknologi Sepuluh November Surabaya. Penelitian yang dilakukan Irawan bertujuan untuk menganalisa model pembinaan industri kecil di Jawa Timur. Proses penilaian Fuzzy Quality Function Deployment pada penelitian ini menggunakan fungsi keanggotaan Triangular Fuzzy Number. Dengan metode yang sama, Biringkanae (2010) yang melakukan analisa upaya-upaya apa saja yang dilakukan dalam peningkatan kualitas di PT. Tunas Asri juga menggunakan metode Quality Function Deployment (QFD) dan Fuzzy Quality Function Deployment (FQFD) dalam penelitiannya.

\section{METODOLOGI PENELITIAN}

Penelitian ini menjelaskan langkah-langkah pengerjaan yang akan dilakukan untuk mengevaluasi kualitas produk menggunakan metode QFD. Dalam mengevaluasi kualitas produk dilakukan analisis tentang permasalahan yang dihadapi oleh pengrajin yang ada di Industri kerajinan terkait tentang performa teknologi yang mereka miliki. Dari analisis ini kemudian diberikan usulan perbaikan bagi para pengrajin dalam usaha meningkatkan performa teknologi yang mereka miliki agar siap bersaing di pasaran. Diagram Alir metodologi penelitian dapat dilihat pada Gambar 1 berikut ini.

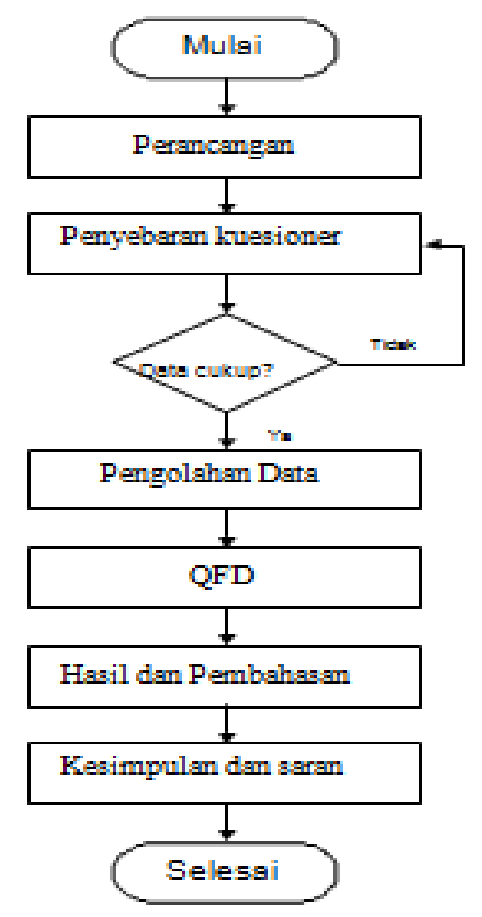

Gambar 1. Diagram alir QFD

\section{HASIL DAN PEMBAHASAN}

Langkah pertama yang dilakukan dalam mengevaluasi kualitas produk menggunakan metode QFD adalah mengidentifikasi dan mengumpulkan keinginan konsumen (atribut kualitas). Pengrajin batik yang dianalisis dalam penelitian ini adalah pengrajin Batik A dengan kompetitornya Batik B dan Batik C. Atribut kualitas yang mempengaruhi kepuasan konsumen serta menjadi pertimbangan konsumen dalam memilih produk dirumuskan pada Tabel 1. 
Tabel 1. Atribut kualitas

\begin{tabular}{c|l}
\hline Butir & \multicolumn{1}{|c}{ Atribut } \\
\hline 1 & Warna tahan lama \\
2 & Warna alami/natural (berasal dari warna alam) \\
3 & Warna tidak alami / tidak natural (berasal dari zat kimia) \\
4 & Desain tradisional \\
5 & Desain modern \\
6 & Desain perpaduan antara tradisional dan modern \\
7 & Desain motif tulis (batik tulis) \\
8 & Desain motif cap (batik cap) \\
9 & Desain motif printing (textile/ batik printing) \\
10 & Desain motif perpaduan tulis dan cap (batik kombinasi) \\
11 & Desain motif perpaduan printing dan tulis \\
12 & Desain motif perpaduan printing dan cap \\
& \multicolumn{1}{|c}{ Tabel 1. Atribut kualitas (lanjutan) } \\
\hline 13 & Kualitas kain yang digunakan \\
14 & Kualitas warna \\
15 & Model mengikuti yang sedang trend \\
16 & Terdapat banyak warna dalam satu produk \\
17 & Tidak terlalu banyak warna dalam satu produk \\
18 & Keunikan model dan desain produk \\
19 & Keunikan warna \\
20 & Produk sesuai fungsinya \\
21 & Mudah dalam perawatan \\
22 & Keamanan bahan -bahan yang dihubungkan dengan kesehatan \\
\hline
\end{tabular}

Pengolahan data QFD:

Setelah dilakukan uji validitas dan reliabilitas pada atribut-atribut yang ada, atribut yang valid dan reliable kemudian dijadikan customer needs, yang dapat dilihat pada Tabel 2.

Tabel 2. Customer needs

\begin{tabular}{c|l}
\hline Simbol & \multicolumn{1}{c}{ Atribut } \\
\hline S1 & Warna tahan lama \\
S2 & Warna alami/warna natural (warna alam) \\
S3 & Desain tradisional \\
S4 & Desain modern \\
S5 & Desain tradisional dan modern \\
S6 & Desain tulis (batik tulis) \\
S7 & Desain cap (batik cap) \\
S8 & Desain kombinasi (perpaduan tulis dan cap) \\
S9 & Kualitas kain \\
S10 & Kualitas warna \\
S11 & Model mengikuti yang sedang trend \\
S12 & Keunikan model dan desain produk \\
S13 & Keunikan warna \\
S14 & Mudah dalam perawatan \\
\hline
\end{tabular}


Customer Satisfaction Performance (CSP) bertujuan untuk mengetahui seberapa puas konsumen terhadap tiap atribut yang ada pada Batik A, Batik B, dan Batik C yang dijelaskan pada Tabel 3.

\section{Tabel 3. Customer Satisfaction Performance (CSP)}

\begin{tabular}{c|l|c|c|c}
\hline No & Atribut & \multicolumn{3}{|c}{ Nilai Customer Satisfaction } \\
\cline { 3 - 5 } 1. & Batik A A & Batik B & Batik C \\
2. & Warna tahan lama & 3,50 & 3,43 & 3,37 \\
3. & Warna alami/ natural (berasal dari warna alam) & 3,10 & 3,73 & 3,10 \\
4. & Desain tradisional & 3,33 & 3,37 & 3,30 \\
5. & Desain modern & 3,33 & 3,10 & 3,40 \\
6. & Desain perpaduan motif tulis (batik tulis) & 3,20 & 3,00 & 3,27 \\
7. & Desain motif cap (batik cap) & 3,63 & 3,57 & 3,53 \\
8. & Desain motif perpaduan tulis dan cap (batik kombinasi) & 3,33 & 3,40 & 3,33 \\
9. & Kualitas kain yang digunakan & 3,23 & 3,43 & 3,40 \\
10. & Kualitas warna & 3,57 & 3,30 & 3,20 \\
11. & Model mengikuti yang sedang trend & 2,97 & 3,43 \\
12. & Keunikan model dan desain produk & 3,33 & 3,43 & 3,77 \\
13. & Keunikan warna & 3,30 & 3,57 & 3,50 \\
14. & Mudah dalam perawatan & 3,53 & 3,43 & 3,10 \\
\hline
\end{tabular}

Dari Tabel 3, dapat dilihat bahwa atribut yang memiliki nilai kepuasan konsumen paling tinggi untuk Batik A adalah "desain motif tulis" $(3,63)$. Hal ini dikarenakan sebagian besar produk yang diproduksi Batik A merupakan batik tulis yang merupakan pesanan dari para pelanggan. Sedangkan atribut yang memiliki nilai kepuasan konsumen paling rendah adalah "model mengikuti yang sedang trend", atribut ini perlu dikembangkan agar nilai kepuasan pelanggan terhadap atribut ini meningkat.

Voice of company:

Kebutuhan konsumen yang diterjemahkan ke dalam kebutuhan teknis sebagai berikut.

a. bahan mori/kain,

b. bahan pewarna,

c. inovasi desain,

d. inovasi model,

e. inovasi motif,

f. inovasi warna,

g. teknik pembatikan,

h. teknik pewarnaan,

i. proses pembatikan,

j. proses pewarnaan.

Final Technical Setting:

Final technical setting merupakan kontribusi karakteristik teknis kepada performansi produk/jasa secara keseluruhan. Kontribusi ini dapat diperoleh dengan mengurutkan peringkat karakterisik teknis, berdasarkan bobot kepentingan dan kebutuhan pelanggan. Kontribusi kebutuhan teknis pada penelitian ini dijelaskan pada Tabel 4. 
Tabel 4. Final technical setting

\begin{tabular}{c|l|c|c}
\hline No. & \multicolumn{1}{|c|}{ Kebutuhan teknis } & AI & RI \\
\hline 1 & Bahan mori/ kain & 26.803 & 6.40 \\
2 & Bahan pewarna & 41.402 & 9.88 \\
3 & Inovasi desain & 68.389 & 16.32 \\
4 & Inovasi model & 26.232 & 6.26 \\
5 & Inovasi motif & 43.948 & 10.49 \\
6 & Inovasi warna & 49.328 & 11.77 \\
7 & Teknik pembatikan & 53.896 & 12.86 \\
8 & Teknik pewarnaan & 48.283 & 11.52 \\
9 & Proses pembatikan & 30.946 & 7.38 \\
10 & Proses pewarnaan & 29.826 & 7.12 \\
\hline
\end{tabular}

Dari Tabel 4 dapat dilihat bahwa kontribusi karakteristik teknis kepada performansi produk/jasa secara keseluruhan, berturut-turut :
a. Inovasi desain
f. Bahan pewarna
b. Teknik pembatikan
g. Proses pembatikan
c. Inovasi warna
d. Teknik pewarnaan
h. Proses pewarnaan
e. Inovasi motif
i. Bahan kain
j. Inovasi model

Analisis Data:

Berdasarkan pengolahan data yang dilakukan, diperoleh urutan prioritas customer needs (WHAT'S) dan urutan prioritas kebutuhan teknis (HOW'S) menggunakan QFD. Urutan prioritas customer needs (WHAT'S) menggunakan QFD, sebagai berikut.
a. Warna tahan lama,
b. Mudah dalam perawatan,
i. Model mengikuti yang sedang trend,
c. Kualitas warna,
d. Desain motif tulis (batik tulis),
j. Desain motif cap (batik cap),
e. Kualitas kain yang digunakan,
k. Keunikan warna,
f. Desain modern,
g. Desain motif perpaduan antara tulis dan cap,
1. Keunikan model dan desain produk,
m. Desain tradisional,
n. Desain perpaduan antara tradisional dan modern.

h. Warna alami/natural (warna alam),

Urutan prioritas kebutuhan teknis (HOW'S) menggunakan QFD, sebagai berikut.
a. Inovasi desain,
f. Bahan pewarna,
b. Teknik pembatikan,
g. Proses pembatikan,
c. Inovasi warna,
h. Proses pewarnaan,
d. Teknik pewarnaan,
e. Inovasi motif,
i. Bahan mori/kain,
j. Inovasi model

Penentuan usulan perbaikan:

Untuk menentukan jumlah langkah teknis yang akan diprioritaskan, maka digunakan diagram pareto. Dalam pembuatan diagram pareto, kebutuhan teknis diurutkan dari persentase paling tinggi ke persentase yang kecil yang dinyatakan pada Tabel 5. Diagram pareto untuk urutan kebutuhan teknis menggunakan QFD digambarkan dalam Gambar 2.

Sedangkan hubungan antara voice of customer dengan voice of company digambarkan didalam House of Quality, sebagaimana digambarkan dalam Gambar 3. Di dalam House of 
Quality, hubungan antara voice of customer (Whats) dengan voice of company (Hows) merupakan penilaian manajemen dengan mengacu pada kondisi real yang ada.

Tabel 5. Urutan kebutuhan teknis QFD

\begin{tabular}{c|l|c|c}
\hline No. & Kebutuhan Teknis & Relative Importance QFD $\mathbf{~ \% ) ~}$ & Kumulatif RI (\%) \\
\hline 1 & Inovasi desain & 16,32 & 16,32 \\
2 & Teknik pembatikan & 12,86 & 29,18 \\
3 & Inovasi warna & 11,77 & 40,95 \\
4 & Teknik pewarnaan & 11,52 & 52,47 \\
5 & Inovasi motif & 10,49 & 62,96 \\
6 & Bahan pewarna & 9,88 & 72,84 \\
7 & Proses pembatikan & 7,38 & 80,22 \\
8 & Proses pewarmaan & 7,12 & 87,34 \\
9 & Bahan mori/ kain & 6,40 & 93,74 \\
10 & Inovasi model & 6,26 & 100.00 \\
\hline
\end{tabular}

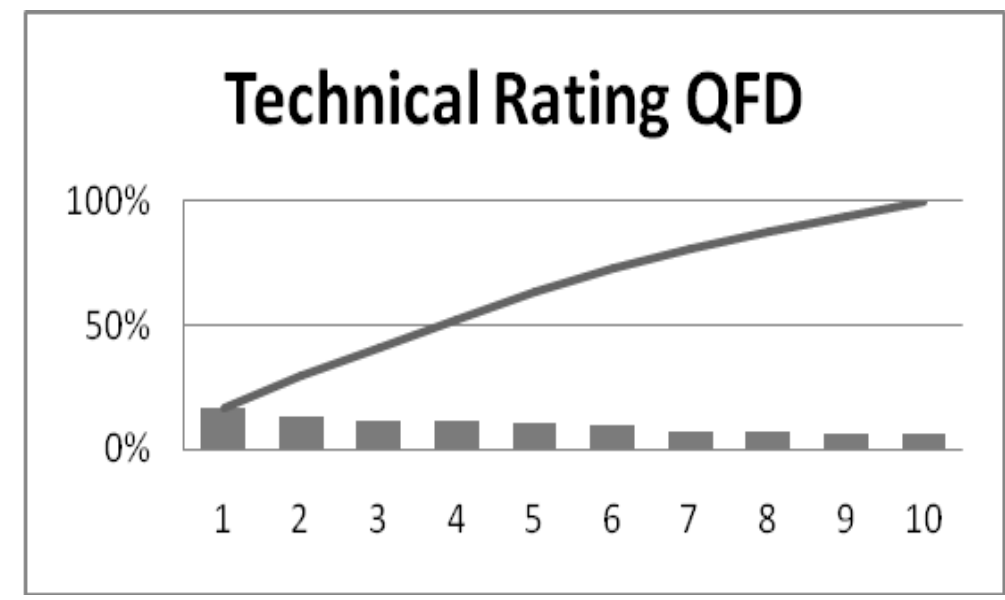

Gambar 2. Diagram Pareto technical rating QFD

Berdasarkan Gambar 2, prioritas usulan menggunakan QFD, berturut-turut sebagai berikut.
a. Inovasi desain,
b. Teknik pembatikan,
c. Inovasi warna,
d. Teknik pewarnaan,
e. Inovasi motif, dan
f. Bahan pewarna. 


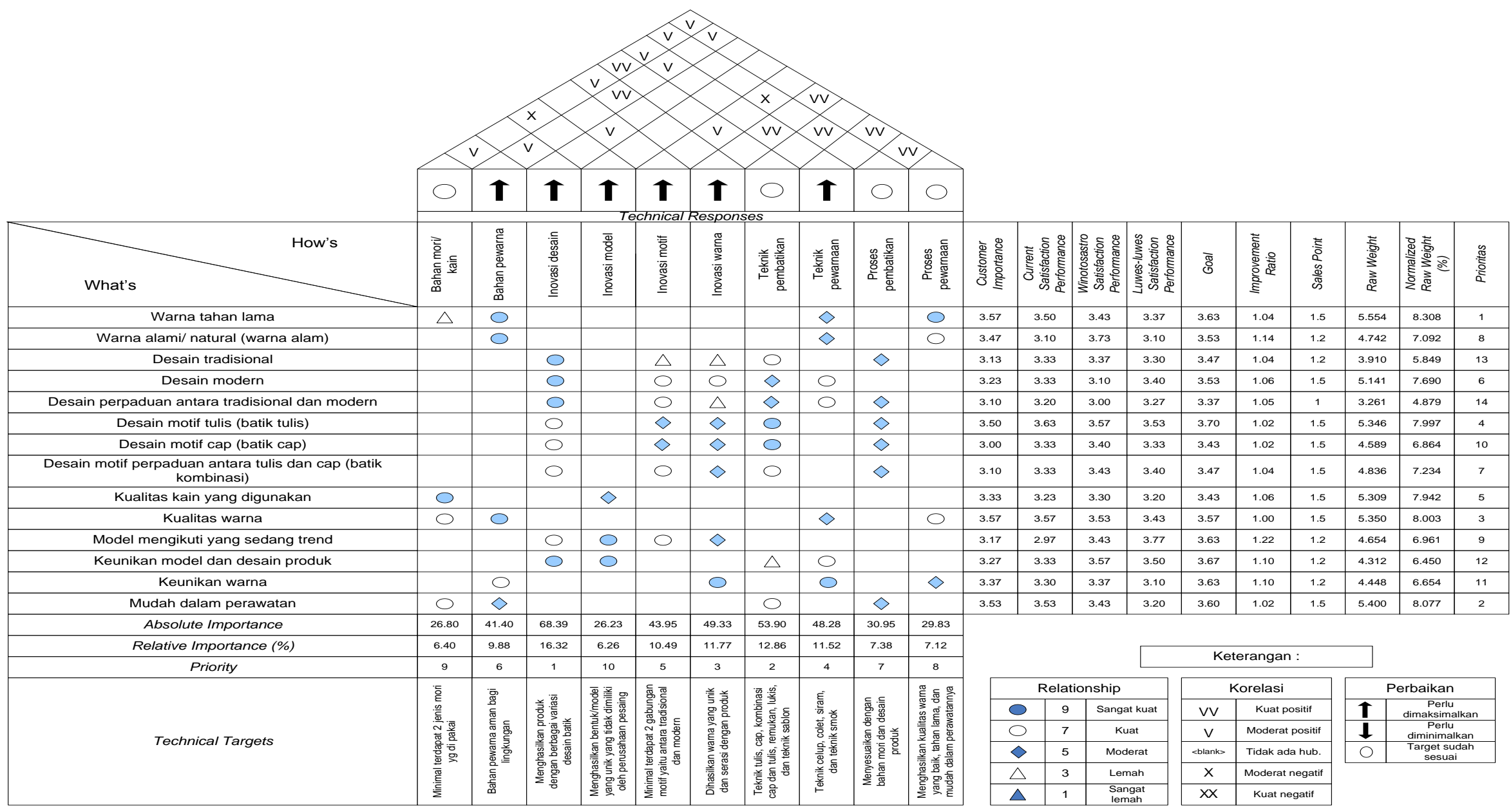

Gambar 3. House of Quality 


\section{KESIMPULAN}

Hasil evaluasi kualitas produk pada industri kerajinan batik menggunakan metode Quality Function Deployment (QFD), prioritas usulan atau hal utama yang harus dilakukan oleh Batik A menghadapi kompetitornya Batik B dan Batik C dalam upaya perbaikkan kualitas produknya, berturut-turut: inovasi desain, teknik pembatikan, inovasi warna, teknik pewarnaan, inovasi motif, dan bahan pewarna.

\section{DAFTAR PUSTAKA}

[1] Adriantantri Emmalia, 2008, Aplikasi Metode Quality Function Deployment (QFD) Dalam Usaha Memenuhi Kepuasan Pelanggan Terhadap Produk AQUA Gelas $240 \mathrm{ml}$ pada Pt. Tirta Investama Pandaan, Fakultas Teknologi Industri Institut Teknologi Nasional (ITN), Malang.

[2] Anggraini Melani, 2011, Pengembangan Alat Ukur Komponen Teknologi dan Evaluasi Kualitas Produk pada Industri Kerajinan Dengan Metode Teknometrik dan Quality Function Deployment (QFD)(Studi Kasus pada Industri Kerajinan Batik di Yogyakarta), Thesis Teknik Mesin dan Teknik Industri, UGM, Yogyakarta.

[3] Biringkanae Sumarniawan, 2010, Perbandingan Quality Function Deployment dengan Fuzzy Quality Function Deployment Dalam Pemilihan Strategi Untuk Peningkatan Kualitas Produk (Studi Kasus PT. Tunas Asr), Skipsi Teknik Mesin dan Teknik Industri, UGM, Yogyakarta.

[4] Cohen, L., 1995, Quality Function Deployment: How to Make QFD Work for you. Addison-Wesley Publication Company, MA.

[5] Ginting Rosnani, 2010, Perancangan Produk, Penerbit Graha Ilmu, Yogyakarta.

[6] Irawan D., 2002, Aplikasi Metode Fuzzy Quality Function Deployment untuk Menganalisa Model Pembinaan Industri Kecil di Jawa Timur, Institut Teknologi Sepuluh November, Surabaya.

[7] Nasution Arman Hakim, 2006, Manajemen Industri, Penerbit Andi Offset, Yogyakarta.

[8] Nawaz Syarif dan K. Ramanathan, 1991, Measuring Contribution of Technology for Policy Analysis, Asean Institute of Technology, diakses 17 Agustus 2010, at http://www.systemdynamics.org/conference/1991/proceed/main-pdfs/sharif534.pdf.

[9] Setiawati puspita, 2008, Kupas Tuntas Teknik Proses Membatik Dilengkapi Teknik Menyablon, cetakan kedua, Absolut, Yogyakarta.

[10] Samsi Sri Soedewi, 2010, Teknik dan Ragam Hias Batik, Balai Besar Kerajinan Batik, Yogyakarta. 